\title{
Arquitectura religiosa del siglo XXI en España
}

Reseña de libro

\section{[Twenty-first century religious architecture} in Spain]

\section{Book review}

\section{Andrés Martínez-Medina}

Universidad de Aicante, España andresm.medina@ua.es 


\section{Esteban Fernández-Cobián}

Universidade da Coruña

A Coruña, 2019

ISBN: 978-84-9749-759-6

Los últimos veinticinco años del siglo XX (1975-2000) no fueron un periodo muy fértil en los medios para las arquitecturas religiosas en Occidente, no porque no se construyeran, sino porque quizás la cantidad y calidad de las mismas habían disminuido respecto al cuarto de siglo precedente de reconstrucción europea (1950-1975) y a que ni ocuparon portadas y páginas de revistas porque la crítica especializada no les prestó suficiente atención. Pero todo esto ha cambiado en el planeta y, en particular, en España, desde que se estrenó el año 2000, baste recordar el número que, en 2002, $A V$-Monografías dedicó a los "Recintos Religiosos. Sacred Spaces: from Gaudí to Moneo" (con un claro homenaje a la arquitectura española dentro del repaso mundial), casi con la intención de construir un canon de los templos cristianos de la pasada centuria de la mano de un nutrido grupo de maestros de la modernidad: desde Wright hasta Siza, para completar esta selección con una muestra panorámica sobre la arquitectura religiosa en el tránsito al nuevo mile-

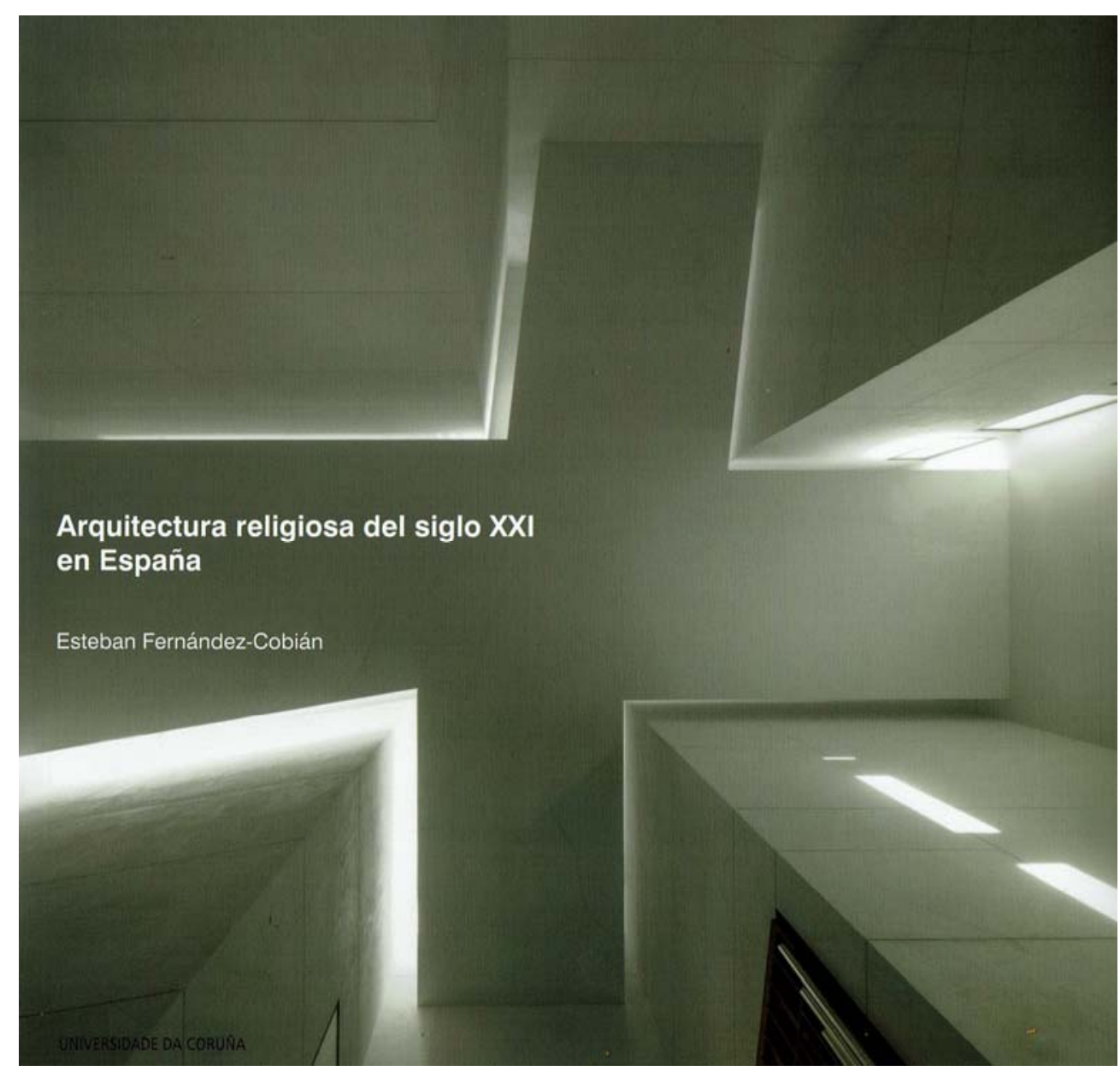

nio. 
Arquitectura religiosa del siglo XXI en España, como su título indica, es un libro que trata de recoger y sintetizar el conjunto de iglesias, templos y capillas (fundamentalmente de nueva planta, pero también de intervención sobre otras ya existentes o espacios ya en uso) proyectado y construido en España en las últimas dos décadas (2000-2020) y que mayor difusión y reconocimiento han tenido. Se reúnen para la ocasión un total de veintiséis obras, en su mayoría de culto católico (salvo una evangélica y otra interconfesional), cuya elección, como dice el autor, Esteban Fernández-Cobián (experto en arquitectura sacra), es personal: "un criterio que se ha apoyado exclusivamente en valores arquitectónicos" (p. 11) que, en parte, viene avalado por el hecho de que "casi todas [estas obras] han sido publicadas en foros digitales (...) y en revistas especializadas”. De nuevo emerge el apoyo mediático para validar los supuestos valores, instrumento que se expande ahora desde las ediciones impresas hacia las publicaciones virtuales. Y es que los tiempos, más que nunca, para los medios y la información, han cambiado. Un valor añadido es que algunos de los ejemplos incluidos vienen avalados por convocatorias previas (pocas) o por premios en concursos a obras terminadas y en uso.

El libro, de formato cuadrado (muy recurrente en la tradición de publicaciones de arquitectos para arquitectos) y bastante pulcro en su presentación, se formaliza con una estructura sencilla y clásica. A parte de los preceptivos datos de identificación e índice, aparece un sugerente ensayo del investigador en el que se pregunta acerca de las características propias que definen y singularizan los espacios sagrados, en particular, los vinculados con el cristianismo. Este texto sirve de presentación del elenco y da paso a los veintiséis templos que, uno a uno, se despliegan a continuación; estos ocupan en cada caso un cierto número de páginas para dar cabida al reportaje fotográfico (casi siempre 'de autor', no necesariamente de los autores), a los abundantes planos aportados por los artífices de esta muestra y a las memorias explicativas y de contexto redactadas por los arquitectos autores intelectuales y materiales de las obras. Todo ello permite tener un cierto discurso coral que pone el énfasis, en cada caso, en aquellos aspectos que más han interesado a sus artífices. Conviene puntualizar que cada uno de estos apartados por obra se abre con el nombre de la iglesia, la ciudad donde se ubica y las fechas de proyecto y conclusión, quedando los nombres de los estudios profesionales en un margen superior, transfiriendo un cierto protagonismo de los arquitectos a la congregación de fieles que suele ser anónima; en la última página de cada ejemplo aparece su ficha técnica. El libro se cierra con un mapa de España donde se ubican las ciudades receptoras de estas arquitecturas. 
Dar un repaso y ejercer una valoración de la selección puede ser pretencioso, pero sí convendría apuntar que, como nos recuerda el autor, "El lenguaje de todas estas iglesias es abstracto" (p. 19) y que el amplio repertorio desplegado se corresponde con programas modestos: de barrio (hay un buen número de iglesias), de peregrinación (ermitas), de instituciones (capillas, algunas para el Santísimo) y discretas intervenciones (en sedes docentes y académicas). No obstante, a pesar de algunos revestimientos algo austeros y fríos por la precipitación de las fotografías recién terminados los espacios sacros, conviene destacar el ingenio y la capacidad de los arquitectos para resolver programas litúrgicos en espacios mínimos o difíciles o en lugares muy humildes. Añadamos la versatilidad material de acabados y texturas (siempre con paletas reducidas en cada obra) y el especial cuidado puesto al manipular la luz que entra al interior; un interior que, como nos recuerda M. Eliade, según Quetglas, es un nuevo exterior, más vasto aún que aquel del que se procede. Y es que templum (templo) y tempus (tiempo) tienen un mismo origen. $\mathrm{Y}$ todo ello, en una arquitectura tan arriesgada porque trata de hacer visible lo invisible, puede considerarse un valor añadido a la obra desde el saber hacer profesional. El libro, no solo ofrece un panorama sobre la arquitectura religiosa reciente en España, invita a la reflexión. 